\title{
Importance of the sick day rule: a case of prerenal acute kidney injury after COVID-19 vaccination in a patient with chronic kidney disease
}

\author{
Yoshihiro Nakamura $^{1}$ D $\cdot$ Yoshinari Yasuda ${ }^{2} \cdot$ Katsuaki Shibata $^{1} \cdot$ Michiko Yamazaki $^{1} \cdot$ Taishi Yamakawa $^{1}$
}

Received: 8 September 2021 / Accepted: 26 September 2021 / Published online: 2 October 2021

(c) Japanese Society of Nephrology 2021

\section{To the Editor:}

Chronic kidney disease (CKD) patients have substantially increased risk of severe coronavirus disease 2019 (COVID19) and should be prioritized for vaccination [1]. We report a case of prerenal acute kidney injury (AKI) after COVID19 vaccination in a CKD patient using renin-angiotensin system inhibitor (RASi) and diuretics.

An 87-year-old woman was inoculated with a second dose of the BNT162b2 mRNA COVID-19 vaccine 1 week before admission. After the second vaccination, she experienced loss of appetite, but continued medication. Two days before admission, she had difficulty in walking. On admission, she was transferred to the emergency department because of disorder of consciousness. Her medical history included hypertension, hyperlipidemia, CKD G4, chronic heart failure, and aortic stenosis. She was on carvedilol ( $5 \mathrm{mg} /$ day), nifedipine (40 mg/day), telmisartan (40 mg/day), allopurinol (200 mg/ day), furosemide (20 mg/day), trichlormethiazide (1 mg/ day), tolvaptan $(7.5 \mathrm{mg} /$ day $)$, rosuvastatin $(2.5 \mathrm{mg} /$ day $)$, lansoprazole (15 mg/day), and aspirin (100 mg/day). On admission, the Glasgow Coma Scale (GCS) score was 7/15. Her temperature was $35.9{ }^{\circ} \mathrm{C}$; blood pressure, $78 / 38 \mathrm{mmHg}$; pulse, 49 beats/min; respiratory rate, 20 breaths/min; and oxygen saturation, $100 \%$ on administered oxygen $(6 \mathrm{~L} / \mathrm{min}$, mask). Physical examination was unremarkable, except for systolic murmur and dry mouth. Her body weight was $37.2 \mathrm{~kg}$. Laboratory findings are presented in Table 1. Electrocardiogram showed a tentorial T wave. Kidney ultrasound revealed renal atrophy and no renal pelvis dilation. She was

Yoshihiro Nakamura

nakamurashift@yahoo.co.jp

1 Department of Nephrology, Toyohashi Municipal Hospital, 50 Hakkennishi, Aotake-cho, Toyohashi 441-8570, Japan

2 Department of Nephrology, Nagoya University Graduate School of Medicine, 65 Tsurumai-cho, Showa-ku,

Nagoya 466-8550, Japan diagnosed with AKI, uremic encephalopathy, and bradycardia induced by hyperkalemia and carvedilol. Normal saline, 10 -mL calcium gluconate $8.5 \%$ solution, and $10 \mathrm{U}$ of regular insulin with $25 \mathrm{~g}$ of glucose ( $50 \mathrm{~mL}$ of a $50 \%$ solution) were administered. Hemodialysis was performed for $3 \mathrm{~h}$ on the day of admission and the following day. GCS scores of 14/15 and urine output were obtained, and dialysis was discontinued. Based on the history of loss of appetite, hypotension on admission, and reversible acute kidney injury, prerenal AKI was diagnosed. Three weeks after admission, her serum creatine level and body weight were $1.15 \mathrm{mg} / \mathrm{dL}$ and $42.4 \mathrm{~kg}$, respectively. At discharge, she was prescribed amlodipine (2.5 mg/day), furosemide (20 mg/day), rosuvastatin $(2.5 \mathrm{mg} /$ day), lansoprazole (15 mg/day), and aspirin (100 mg/day).

The strong temporal association with vaccination suggests that the loss of appetite was due to vaccination, which led to prerenal AKI and hyperkalemia.

Currently, more individuals are being inoculated with COVID-19 vaccine. The reported side effects of the BNT162b2 mRNA COVID-19 vaccine include fever (21.9\%), nausea (15.9\%), and decreased appetite (5.7\%) [2].

Nephrologists often encounter AKI because of acute illness in CKD patients treated with RASi. The "sick day rule" was proposed in patients at risk of AKI [3]. Although evidence is weak, CKD patients are recommended to be checked on regular visits, to temporarily discontinue RASi, diuretics, nonsteroidal anti-inflammatory drugs, and metformin when they experience acute symptoms (e.g., vomiting, diarrhea, and fever) $[4,5]$.

Therefore, CKD patients on RASi or diuretics may be better advised before COVID-19 vaccination to temporarily discontinue such drugs and consult a hospital when they experience acute illness. Further studies are needed to clarify when RASi or diuretic drugs should be discontinued after COVID-19 vaccination. 
Table 1 Laboratory findings

\begin{tabular}{|c|c|c|c|}
\hline \multicolumn{2}{|l|}{ Serum biochemistry } & \multicolumn{2}{|l|}{ Arterial blood gas analysis } \\
\hline Urea, mg/dL & 225 & $\mathrm{pH}$ & 7.179 \\
\hline Creatinine, $\mathrm{mg} / \mathrm{dL}$ & 8.2 & $\mathrm{pO}_{2}$ (oxygen $6 \mathrm{~L} / \mathrm{min}$, mask), $\mathrm{mmHg}$ & 278 \\
\hline $\mathrm{eGFR}, \mathrm{mL} / \mathrm{min} / 1.73 \mathrm{~m}^{2}$ & 4 & $\mathrm{pCO}_{2}, \mathrm{mmHg}$ & 25.4 \\
\hline Uric acid, $\mathrm{mg} / \mathrm{dL}$ & 7.4 & $\mathrm{HCO}^{-}, \mathrm{mmol} / \mathrm{L}$ & 9.1 \\
\hline Sodium, $\mathrm{mmol} / \mathrm{L}$ & 137 & Urinalysis & \\
\hline Potassium, mmol/L & 6.3 & $\mathrm{pH}$ & 5.0 \\
\hline Chloride, $\mathrm{mmol} / \mathrm{L}$ & 96 & Urinary-specific gravity & 1.016 \\
\hline AST, U/L & 30 & Protein & $1+$ \\
\hline $\mathrm{ALT}, \mathrm{U} / \mathrm{L}$ & 9 & Occult blood & Negative \\
\hline CK, IU/L & 617 & Sodium, mEq/L & 32.3 \\
\hline $\mathrm{LDH}, \mathrm{U} / \mathrm{L}$ & 288 & Potassium, $\mathrm{mEq} / \mathrm{L}$ & 33.7 \\
\hline Complete blood count & & Chloride, $\mathrm{mEq} / \mathrm{L}$ & 17.4 \\
\hline $\mathrm{WBC}, / \mu \mathrm{L}$ & 5840 & Urea, mg/dL & 371.4 \\
\hline $\mathrm{Hb}, \mathrm{g} / \mathrm{L}$ & 9.3 & Creatinine, $\mathrm{mg} / \mathrm{dL}$ & 231.9 \\
\hline $\mathrm{Plt}, \times 10^{9} / \mathrm{L}$ & 11.4 & & \\
\hline
\end{tabular}

$e G F R$ estimated glomerular filtration rate, $A S T$ aspartate aminotransferase, $A L T$ alanine transaminase, $C K$ creatine kinase, $L D H$ lactate dehydrogenase, $W B C$ white blood cell, $H b$ hemoglobin, Plt platelet

Acknowledgements We extend our sincere gratitude to Dr. Nozomi Mori for providing constructive comments and warm encouragement.

\section{Declarations}

Conflict of interest All the authors have declared no competing interest.

Ethics approval This article does not contain any studies with human participants or animals performed by any of the authors.

Informed consent Written informed consent was obtained from the patient.

\section{References}

1. Windpessl M, Bruchfeld A, Anders HJ, Kramer H, Waldman M, Renia L, et al. COVID-19 vaccines, and kidney disease. Nat Rev Nephrol. 2021;17(5):291-3.
2. Kadali RAK, Janagama R, Peruru S, Malayala S. Side effects of BNT162b2 mRNA COVID-19 vaccine: a randomized, cross-sectional study with detailed self-reported symptoms from healthcare workers. Int J Infect Dis. 2021;106:376-81.

3. Think Kidneys. Sick day guidance in patients at risk of acute kidney injury: a position statement from the Think Kidneys Board. 2018; c(January):1-5. https://www.thinkkidneys.nhs.uk/aki/wpcontent/uploads/sites/2/2018/01/Think-Kidneys-Sick-Day-Guida nce-2018.pdf. Accessed 18 Aug 2021.

4. Weir VA, Methven S. A practical guide to diagnosis and assessment of chronic kidney disease for the non-nephrologist education. J R Coll Physicians Edinb. 2020;50(1):67-74.

5. Martindale AM, Elvey R, Howard SJ, McCorkindale S, Sinha $\mathrm{S}$, Blakeman T. Understanding the implementation of "sick day guidance" to prevent acute kidney injury across a primary care setting in England: a qualitative evaluation. BMJ Open. 2017;7(11):e017241.

Publisher's Note Springer Nature remains neutral with regard to jurisdictional claims in published maps and institutional affiliations. 